\title{
Multi-level immune response network in mild-moderate Chronic Obstructive Pulmonary Disease (COPD)
}

\author{
Tamara Cruz ${ }^{1,2+}$, Alejandra López-Giraldo ${ }^{1,2,3 \dagger}$, Guillaume Noell ${ }^{1,2}$, Sandra Casas-Recasens ${ }^{1,2}$, Tamara Garcia ${ }^{1,2}$, \\ Laureano Molins ${ }^{3}$, Manel Juan ${ }^{4}$, Marco A. Fernandez ${ }^{5}$, Alvar Agusti ${ }^{1,2,3}$ and Rosa Faner ${ }^{1,2,6^{*}}$ (D)
}

\begin{abstract}
Background: Chronic Obstructive Pulmonary Disease (COPD) is associated with an abnormal pulmonary and systemic immune response to tobacco smoking. Yet, how do immune cells relate within and between these two biological compartments, how the pulmonary infiltrate influences the lung transcriptome, and what is the role of active smoking vs. presence of disease is unclear.

Methods: To investigate these questions, we simultaneously collected lung tissue and blood from 65 individuals stratified by smoking habit and presence of the disease. The immune cell composition of both tissues was assessed by flow cytometry, whole lung transcriptome was determined with Affymetrix arrays, and we used Weighted Gene Co-expression Network Analysis (WGCNA) to integrate results.

Results: Main results showed that: (1) current smoking and the presence of COPD were both independently associated with a reduction in the proportion of lung $T$ cells and an increase of macrophages, specifically those expressing CD80 +CD163+; (2) changes in the proportion of infiltrating macrophages, smoking status or the level of airflow limitation were associated to different WGCNA modules, which were enriched in iron ion transport, extracellular matrix and cilium organization gene ontologies; and, (3) circulating white blood cells counts were correlated with lung macrophages and T cells.

Conclusions: Mild-moderated COPD lung immune infiltrate is associated with the active smoking status and presence of disease; is associated with changes in whole lung tissue transcriptome and marginally reflected in blood.
\end{abstract}

Keywords: Chronic bronchitis, Emphysema, Flow cytometry, Transcriptome, Network analysis

\section{Background}

Tobacco smoking is the main environmental risk factor for COPD, albeit not all smokers develop the disease [1, 2]. It is currently accepted that, in so-called "susceptible smokers", tobacco smoking triggers an abnormal pulmonary and systemic immune response that eventually damages the lung parenchyma and leads to persistent airflow limitation and COPD [1-5]. Yet, some aspects of this pathogenic paradigm are still unclear and require specific

\footnotetext{
* Correspondence: rfaner@clinic.cat

Tamara Cruz and Alejandra López-Giraldo are co-primary authors.

${ }^{1}$ CIBER Enfermedades Respiratorias, Barcelona, Spain

${ }^{2}$ Institut de Recerca Biomedica August Pi i Sunyer (IDIBAPS), Barcelona, Spain

Full list of author information is available at the end of the article
}

research. For instance, although in cross-sectional studies [6-9] the number of inflammatory cells infiltrating the lung parenchyma increase in parallel with the severity of airflow limitation, how do these cells relate among themselves is unknown. Likewise, it is unclear how changes in the pulmonary immune cell network relate to changes in the whole lung transcriptome [10-13]. Besides, given that smoking per se has well recognized effects on the immune system [4, 14], it is important (and challenging) to disentangle the role of disease itself vs. that of active smoking. Finally, previous studies have tried to identify blood surrogate markers of lung changes $[15,16]$, but the relation between different immune cell types in the

(c) The Author(s). 2019 Open Access This article is distributed under the terms of the Creative Commons Attribution 4.0 International License (http://creativecommons.org/licenses/by/4.0/), which permits unrestricted use, distribution, and 
two compartments (i.e. lung and blood) has not been ever assessed.

We hypothesized that a data set that combined lung tissue and circulating blood measurements collected simultaneously in current and former smokers with COPD, as well as controls with normal lung function (current and never smokers), would be a unique asset to: (1) characterize the lung and blood immune cell composition in relation to both smoking status and presence of disease; (2) explore the relationship between the lung immune cell composition and the lung tissue transcriptome; and, finally, (3) construct a multi-level (lung and blood) immune cell correlation network to assess if the lung changes are reflected in the blood.

\section{Methods}

Full methods are provided in the Additional file 1.

\section{Population and ethics}

We prospectively collected clinically relevant information as well as lung tissue and blood samples from 65 patients who required thoracic surgery for lung cancer (Table 1). The lung tissue was from a non-affected location. All participants signed their informed consent, and the Ethics Committee of our institution approved the study (HCB-2012/7731).

\section{Lung tissue processing}

Fresh lung tissue was washed with PBS, enzymatically digested with $0.5 \mathrm{mg} / \mathrm{ml}$ Collagenase $\mathrm{P}$ and $0.1 \mathrm{mg} / \mathrm{ml}$ DNase I (Roche, Germany), incubated at $37^{\circ} \mathrm{C}$ for 30 min, and mechanically digested with GentleMACS Mdissociator tubes (Miltenyi Biotech, Germany).

\section{Measurements}

Lung function

Forced spirometry and carbon monoxide lung capacity (DLCO) were determined according to international recommendations [2] and reference values corresponded to a Mediterranean population [17].

\section{Circulating inflammatory markers}

Circulating venous blood was collected in EDTA tubes (BD, US) in the operating room before surgery started. Total white blood cells counts were quantified with an ADVIA-2120 system (Siemens, Germany). The plasma concentration of high sensitivity $\mathrm{C}$ Reactive Protein (hsCRP) was determined by ultra-sensitive quantitative turbidimetric test (Bayer Diagnostics, Germany).

\section{Flow cytometry}

Immune cell populations were analysed in parallel in blood and lung tissue. Lung tissue homogenates $\left(5 \cdot 10^{5}\right.$ cells) or $50 \mu \mathrm{l}$ of peripheral blood were stained with the corresponding fluorescently conjugate monoclonal antibody mix (Additional file 1: Table S1), incubated at $4{ }^{\circ} \mathrm{C}$ for $30 \mathrm{~min}$ and washed. A minimum of $2 \cdot 10^{5}$ cells per tube were acquired in a FacsCanto (BD Biosciences, US), data was analyzed using FlowJo v10 software (FlowJo LLC, US) Additional file 2: Figures S1-S6.

\section{Transcriptomic analysis}

Total RNA was isolated with PureLink RNA-MiniKit (Life Technologies, US), quantified by Nanodrop (Thermo Scientific, Germany). RNA samples with integrity numbers (RIN) $\geq 7$ (Agilent technologies, Germany), where analysed with the Affymetrix GeneChip Human Genome U219 Array Plate. Only from 53 individuals the mRNA quality was adequate for analysis (Additional file 1: Table

Table 1 Clinical variables of the subjects enrolled in the analysis of the cellular immune response

\begin{tabular}{|c|c|c|c|c|c|}
\hline & Non-Smokers & Smokers & COPD-FS & COPD-CS & \\
\hline & $n=12$ & $n=9$ & $n=16$ & $n=28$ & value \\
\hline Age (years) & $67.6 \pm 9.5$ & $58.0 \pm 9.3$ & $64.5 \pm 8.1$ & $67.8 \pm 7.8$ & 0.0587 \\
\hline Gender (M/F) & $3 / 9$ & $5 / 4$ & $14 / 2$ & $20 / 8$ & 0.0051 \\
\hline Pack/year & - & $36.8 \pm 19.1$ & $48.7 \pm 19.9$ & $51.1 \pm 22.1$ & 0.1830 \\
\hline $\mathrm{BMI}\left(\mathrm{Kg} / \mathrm{m}^{2}\right)$ & $28.0 \pm 6.7$ & $27.4 \pm 5.4$ & $24.9 \pm 3.8$ & $28.0 \pm 3.5$ & 0.0974 \\
\hline $\mathrm{FEV}_{1} / \mathrm{FVC}(\%)$ & $77.9 \pm 4.1$ & $79.1 \pm 10.1$ & $61.7 \pm 6.5$ & $59.9 \pm 7.1$ & 0.0000 \\
\hline $\mathrm{FEV}_{1}$ (\% ref) & $97.3 \pm 8.1$ & $95.1 \pm 7.5$ & $77.1 \pm 13.0$ & $77.3 \pm 18.3$ & 0.0001 \\
\hline DLCO (\% ref.) & $78.3 \pm 16.2$ & $78.9 \pm 11.4$ & $61.6 \pm 9.6$ & $71.4 \pm 14.7$ & 0.0021 \\
\hline WBC $10 \wedge 9 / L$ & $7.5 \pm 2.1$ & $9.3 \pm 4.01$ & $6.5 \pm 2.2$ & $8.6 \pm 2.2$ & 0.0193 \\
\hline Abs Neutrophil count $\left(10^{\wedge} 9 / L\right)$ & $5.0 \pm 2.1$ & $6.1 \pm 4.0$ & $4.0 \pm 1.6$ & $5.5 \pm 1.8$ & 0.0448 \\
\hline hsCRP mg/dl & $0.72 \pm 0.96$ & $8.56 \pm 18.09$ & $0.62 \pm 0.98$ & $2.43 \pm 4.94$ & 0.0954 \\
\hline
\end{tabular}

FS Former smokers, CS Current smokers, WBC white blood cell count, $h s C R P$ high sensitivity C Reactive Protein, BMI Body Mass Index, FEV, Forced expiratory volume $1 \mathrm{~s}, F V C$ forced vital capacity

$P$ value of the kruskall wallis or chi square test 
S2). Raw microarray data has been deposited in GEO (GSE103174).

\section{Data analysis}

Statistical analysis were performed using R [18]. Results are presented as $\mathrm{n}$, proportion, or mean \pm standard deviation. Differences between groups were assessed using the Kruskal-Wallis test, followed by post-hoc contrasts if necessary (Table 2). A linear model after log transformation of variables was used to ascertain the independent contribution of smoking status and presence of disease. $P$ values $<0.05$ were considered significant. Lung-blood immune cell correlation networks were built with $\mathrm{R}$ and visualized using Cytoscape as described elsewhere (Spearman coefficient $r>|0.3|$ and a $p$-value <0.05) [19].

\section{Results}

\section{Participant characteristics}

Table 1 presents the main characteristics of participants. In patients with COPD the proportion of subjects with GOLD grade 1 airflow limitation $(31 \%(n=5)$ vs. $32 \%$ $(n=9))$ and GOLD grade $2(69 \%(n=11)$ vs. $68 \%(n=$ 19)) was similar in former (FS) and current smokers (CS) patients, respectively. DLCO was mildly reduced in COPD patients. Circulating leukocyte and neutrophil

Table 2 Post-hoc analysis on lung cell populations reported as $\%$ of CD45 gated cells

\begin{tabular}{|c|c|c|c|}
\hline Cell population & Group 1 & Group 2 & $P$ value (Mann-Whitney) \\
\hline$\% M \varphi$ & CS-COPD & FS-COPD & 0.004 \\
\hline$\% M \varphi$ & CS-COPD & NS & 0.005 \\
\hline$\%$ Monocytes & CS-COPD & FS-COPD & 0.015 \\
\hline$\%$ Monocytes & CS-COPD & NS & 0.009 \\
\hline$\%$ T cells & CS-COPD & FS-COPD & 0.002 \\
\hline$\%$ T cells & CS-COPD & NS & 0.006 \\
\hline$\%$ T cells & CS-COPD & $S$ & 0.024 \\
\hline$\%$ T CD4+ & CS-COPD & FS-COPD & 0.008 \\
\hline$\%$ T CD8+ & CS-COPD & S & 0.035 \\
\hline$\%$ T CD8+ & CS-COPD & NS & 0.046 \\
\hline$\% M \varphi$ CD80+ CD163- & CS-COPD & FS-COPD & 0.055 \\
\hline$\% \mathrm{M \varphi} C D 80+$ CD163- & CS-COPD & NS & 0.040 \\
\hline$\% \mathrm{M \varphi} C D 80+\mathrm{CD} 163-$ & S & NS & 0.036 \\
\hline$\% M \varphi$ CD80+ CD163- & FS-COPD & S & 0.019 \\
\hline$\% \mathrm{M \varphi}$ CD80 + CD163+ & CS-COPD & FS-COPD & 0.000 \\
\hline$\% \mathrm{M \varphi}$ CD80 + CD163+ & CS-COPD & NS & 0.000 \\
\hline
\end{tabular}

On populations that showed a significantly different distribution between the 4 study groups (Fig. 1 and Additional file 2: Figures S7-S8) a post-hoc analysis was performed using the Mann-Whitney on original values

NS non-smoker, $S$ normal lung function smoker, FS-COPD Former smoker with COPD, CS-COPD Current Smoker with COPD counts and hsCRP plasma levels were increased in current smokers (with or without COPD) (Table 1).

\section{Characterization of lung and blood immune cells}

Figure 1 (panels a and $b$ ) compares the proportion of the different lung immune cell populations studied, expressed as percentage of total CD45 + cells (hematopoietic lineage, a common practice in order to perform immunophenotyping in non-lymphoid tissues [20]) in the four groups investigated. Main differences were observed in current smokers with COPD (COPD-CS) who showed: (1) a significant reduction in the proportion of T-cells that involved both CD4+ and CD8+ T cells (Table 2 and Additional file 2: Figure S7); (2) a significant increase in the proportion of macrophages $(\mathrm{M} \phi)$ (Fig. 1a), of whom a higher percentage expressed both CD80 + CD163+ (Table 2, Additional file 2: Figure S8) and a relative reduction of CD80 + CD163-M $\phi$ (Table 2, Additional file 2: Figure S8); and, (3) a different distribution of lung monocytes between study groups (Fig. 1b) due to an increase of monocytes in COPD-CS (Table 2, Additional file 2: Figure S8D).

As main changes were observed in COPD-CS, next we used a linear model in order to evaluate if both current smoking and presence of COPD have an independent effect. We observed that current smoking was inversely related to the proportion of lung $\mathrm{T}$-lymphocytes $(\beta \mathrm{eta}=$ $-0.111, p$ value $=0.008)$ and positively with that of macrophages $(\mathrm{M} \phi)(\beta$ eta $=0.210, p$ value $=0.001)$ and monocytes $(\beta$ eta $=0.104, p$ value $=0.005)$; while the presence of COPD had an independent but smaller effect $(\mathrm{M} \phi$, ßeta $=0.152, p$ value $=0.05$; T-lymphocytes, $\beta$ eta $=-0.100, p$ value $=0.065$ ).

Finally, the proportion of the different immune cell populations in circulating blood was not different across groups (Fig. 1c and d).

\section{Relationship between lung immune cell population and whole lung transcriptome}

To assess the association between the immune composition of the lung and the biological processes on-going in the lung, we measured the gene expression profile of the whole lung from 53 participants ( $82 \%$ of the total population studied, Additional file 1: Table S2) and used Weighted Gene Co-expression Network Analysis (WGCNA) to integrate the information. WGCNA defines a set of modules of coexpressed genes, and for each provides their "eigengene" value (i.e., the principal component of the expression matrix of the probes within the module). The eigengene can be related to the variables of interest [21], in our case $\mathrm{FEV}_{1}$, the smoking status and the percentage of lung macrophages (the cell population reporting more differences across study groups). 


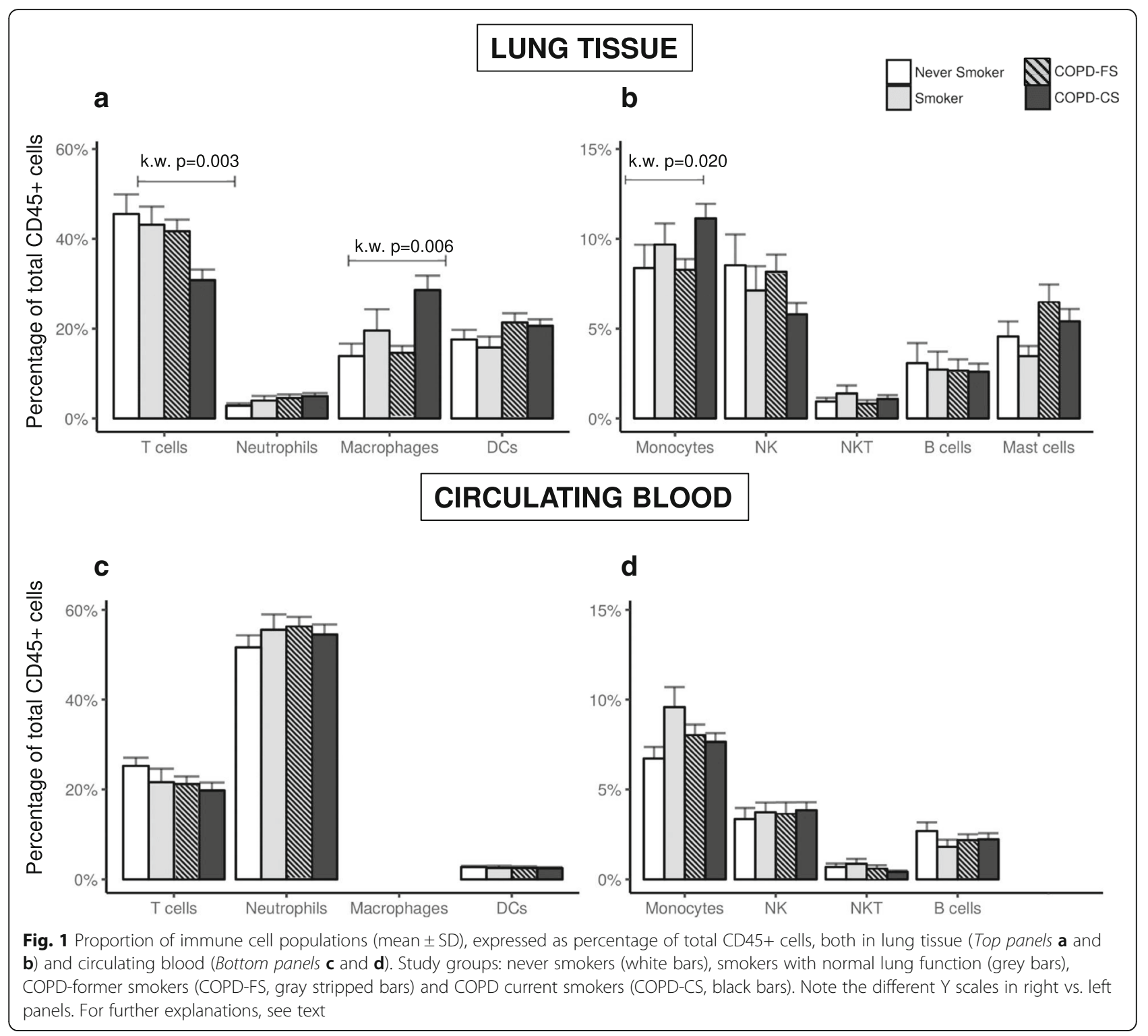

WGCNA identified 23 modules (Additional file 1: Table S3), of them in eight the eigengene was significantly associated with the variables of interest (Fig. 2).

Specifically, we observed that one module (Yellow, $n=$ 645 genes) was associated to the levels of $\mathrm{FEV}_{1}$ and DLCO $\%$ predicted. (Fig. 3) and was enriched in genes associated to the Cilium Organization Gene Ontology biological process term (GO) (Additional file 1: Tables S4-S5).

Three modules were associated both to the smoking status and percentage of infiltrating M $\phi$ (Fig. 3): (i) Tan ( $n=$ 211), enriched for iron metabolism and phospholipid metabolism GO terms (Additional file 1: Tables S4-S5), (iii) Royalblue $(n=86)$, related to T cell activation GO terms (Additional file 1: Tables S4-S5), (iii) Lightcyan $(n=140)$, related to mRNA processing GO terms (Additional file 1: Tables S4-S5).
Three modules were associated to the level of lung $M \phi$ expressing different surface markers (Fig. 2 and Additional file 2: Figure S9): $i$ ) Greenyellow $(n=227)$, especially related to $\mathrm{CD} 80+\mathrm{CD} 163+\mathrm{M} \phi$, with genes enriched in extracellular matrix organization and collagen metabolism GO terms (Additional file 1: Tables S4-S5). Interestingly this module also presented a negative correlation with the levels of DLCO \% ref. (ii) Blue $(n=789)$, related to CD80CD163+ M $\phi$, with genes enriched in ER to Golgi vesicle transport and regulation of translation GO terms (S4-S5). (iii) LightCyan $(n=140)$, related to CD80-CD163+ M with genes enriched in mRNA processing (S4-S5).

Finally, we assessed which of the module genes have been previously identified as differentially expressed in lung tissue of COPD (GSE47460). The 10 genes with highest differential expression (DE) included are reported in 


\begin{tabular}{|c|c|c|c|c|c|}
\hline MODUL & & & & & MAIN GENE ONTOLOGIES \\
\hline Tan & $\begin{array}{l}0.00022 \\
(0.8552)\end{array}$ & $\begin{array}{l}0.11886 \\
(0.0018)\end{array}$ & $\begin{array}{l}0.00385 \\
(0.0016)\end{array}$ & $\begin{array}{l}-0.00136 \\
(0.3577)\end{array}$ & $\begin{array}{l}\text { - Phospholipid catabolism } \\
\text { - Iron ion transport }\end{array}$ \\
\hline Greenyellow & $\begin{array}{l}0.00136 \\
(0.2662)\end{array}$ & $\begin{array}{l}0.04582 \\
(0.2622)\end{array}$ & $\begin{array}{l}0.00271 \\
(0.0348)\end{array}$ & $\begin{array}{l}-0.00307 \\
(0.0376)\end{array}$ & $\begin{array}{l}\text { - Collagen metabolism } \\
\text { - Extracellular matrix organization }\end{array}$ \\
\hline Yellow & $\begin{array}{l}0.00252 \\
(0.0241)\end{array}$ & $\begin{array}{l}-0.04036 \\
(0.2903)\end{array}$ & $\begin{array}{l}0.00186 \\
(0.1252)\end{array}$ & $\begin{array}{l}0.00328 \\
(0.0265)\end{array}$ & - Cilium organization \\
\hline Royalblue & $\begin{array}{c}0.0015 \\
(0.2005)\end{array}$ & $\begin{array}{l}-0.10793 \\
(0.0043)\end{array}$ & $\begin{array}{l}0.00243 \\
(0.0496)\end{array}$ & $\begin{array}{l}0.00042 \\
(0.7742)\end{array}$ & - $\mathrm{T}$ cell activation \\
\hline Lightcyan & $\begin{array}{l}0.00161 \\
(0.1752)\end{array}$ & $\begin{array}{l}0.03559 \\
(0.3738)\end{array}$ & $\begin{array}{l}0.00373 \\
(0.0023)\end{array}$ & $\begin{array}{l}-0.00091 \\
(0.5355)\end{array}$ & - mRNA processing \\
\hline Blue & $\begin{array}{l}0.00037 \\
(0.7621)\end{array}$ & $\begin{array}{l}0.04385 \\
(0.2827)\end{array}$ & $\begin{array}{l}0.00273 \\
(0.0331)\end{array}$ & $\begin{array}{l}0.00078 \\
(0.5968)\end{array}$ & $\begin{array}{l}\text { - Regulation of translation } \\
\text { - ER to Golgi vesicle-med transport }\end{array}$ \\
\hline Pink & $\begin{array}{l}0.00032 \\
(0.7946)\end{array}$ & $\begin{array}{l}-0.07764 \\
(0.0505)\end{array}$ & $\begin{array}{l}0.00291 \\
(0.0207)\end{array}$ & $\begin{array}{l}0.00096 \\
(0.5142)\end{array}$ & - Proteasomal protein catabolism \\
\hline Salmon & $\begin{array}{l}0.00222 \\
(0.0596)\end{array}$ & $\begin{array}{l}-0.0426 \\
(0.2860)\end{array}$ & $\begin{array}{l}0.00246 \\
(0.0508)\end{array}$ & $\begin{array}{l}0.00159 \\
(0.2823)\end{array}$ & - Negative Regulation of translation \\
\hline & FEV1 & $\begin{array}{l}\text { Smoking } \\
\text { status }\end{array}$ & $\mathbf{M} \Phi$ & DLCO & \\
\hline & & & & & 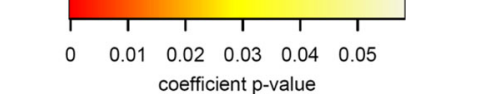 \\
\hline $\begin{array}{l}\text { Fig. } 2 \text { Heat-map of module associa } \\
\text { top number in each cell correspond } \\
\text { terms for the Gene Ontology (GO) t } \\
\text { terms if provided in Additional file } 1\end{array}$ & $\begin{array}{l}\text { with: } t \\
\text { o the ef } \\
\text { ns signif } \\
\text { able } 55 \text {. }\end{array}$ & $\begin{array}{l}\text { the level of } \\
\text { ffect from th } \\
\text { ficantly enri } \\
\text { For further }\end{array}$ & $\begin{array}{l}V_{1} \% \text { pred } \\
\text { linear res } \\
\text { ed for thi } \\
\text { kplanatior }\end{array}$ & $\begin{array}{l}\text { ted, the s } \\
\text { ession an } \\
\text { module o } \\
\text { see text }\end{array}$ & $\begin{array}{l}\text { noking status, and the percentage of Macrop } \\
\text { the bottom number is the } p \text {-value. In the b } \\
\text { tained from the Revigo analysis are displaye }\end{array}$ \\
\hline
\end{tabular}

Table 3. Interestingly, the modules including more differentially expressed genes were the GreenYellow $(n=50)$ and the Yellow $(n=25)$ (Additional file 1: Table S6).

\section{Multi-level (blood and lung) immune cell correlation network}

Finally, we build a multi-level correlation network [22] to investigate the potential relationships between immune cells and clinical variables in both lung and blood (Fig. 3) and observed that: (1) the strongest correlations were found between cells of the same tissue (percentage of lung $\mathrm{M} \phi$ and $\mathrm{T}$ cells $(\mathrm{r}=-0.81)$ and percentage of blood $\mathrm{T}$ cells and neutrophils $(\mathrm{r}=$ - 0.73); (2) eight of the 40 total connections (20\%) involved lung and blood populations (Fig. 2, highlighted with blue edges). Of note, that the percentage of lung $\mathrm{T}$ cells was related to the percentage of blood $\mathrm{T}$ cells $(\mathrm{r}=0.34)$, and the absolute counts of leukocytes $(r=-$ 0.33). Interestingly, the absolute counts of blood leukocytes was also positively correlated with the proportion of lung $\mathrm{M \phi}(\mathrm{r}=0.3)$; (3) $\mathrm{FEV}_{1} \%$ predicted was positively correlated with the proportion of lung $\mathrm{T}$ cells as well as lung and blood NKT cells, whereas it was negatively correlated with the proportion of lung DCs; and, finally (4) Carbon monoxide lung diffusing capacity (DLCO, \% ref.), a well-validated surrogate marker of emphysema [23], was negatively correlated with the proportion of lung $\mathrm{M} \phi, \mathrm{DCs}$ and Monocytes, and positively correlated with those of lung $\mathrm{T}$ cells and peripheral blood $\mathrm{T}$ cells. It is of note that clinical variables were mostly correlated with lung tissue (not blood) populations (Fig. 3).

\section{Discussion}

The main and novel observations of this study are that: (1) the composition of the immune cell infiltrate in the lung (but not in circulating blood) is significantly altered by active smoking and the presence of mild-moderate COPD. These changes are characterized by a reduction in the proportion of lung CD4+ and CD8+ T lymphocytes, and an increase in that of $\mathrm{M \phi}$, especially those expressing CD80 and CD163; (2) the percentage of lung tissue $M \phi$ is associated, independently of the airflow limitation and smoking status, to several modules of co-expressed genes in whole lung 
Circulating blood

Lung tissue

Clinical and lung function variables

General inflammatory markers

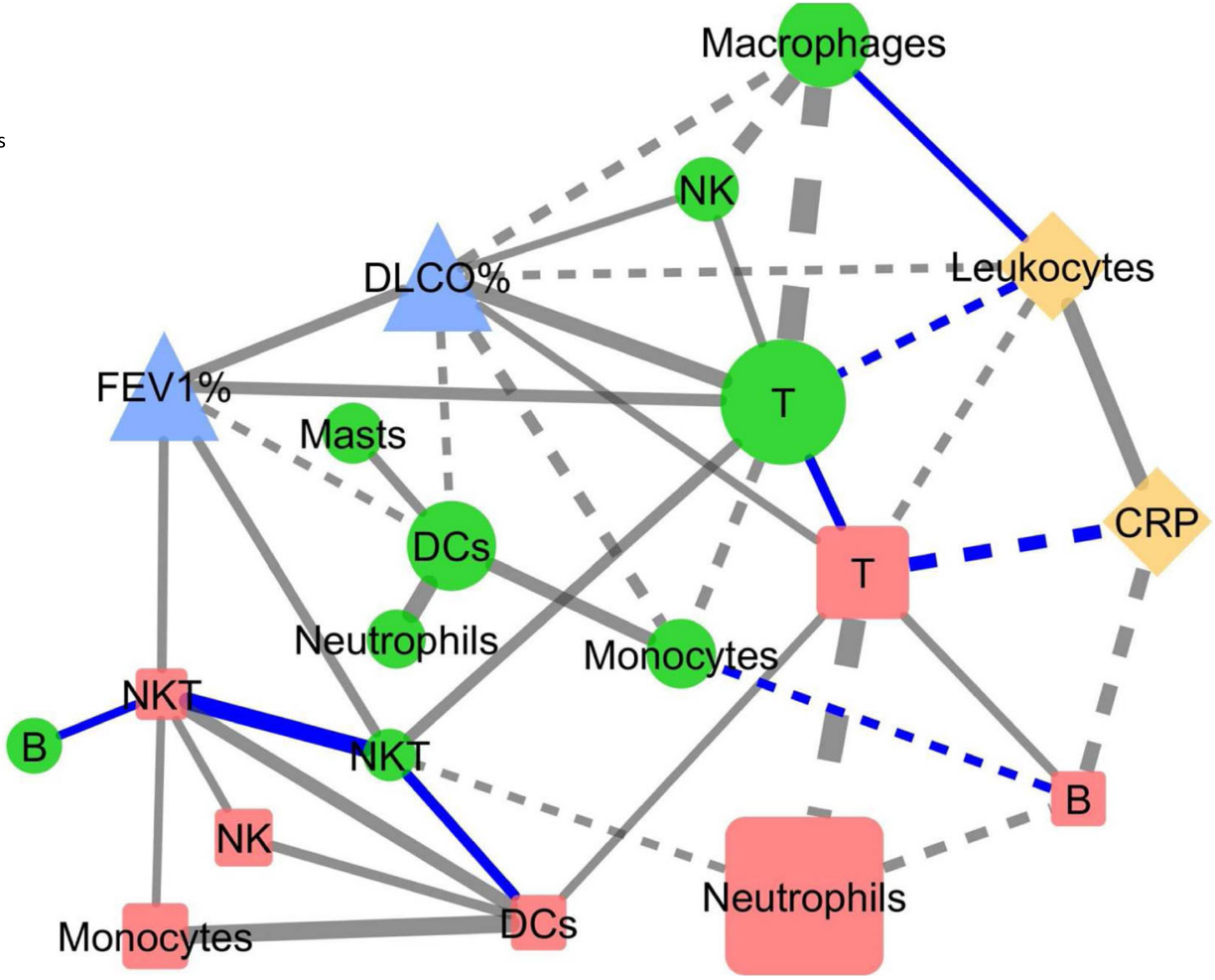

Negative correlation

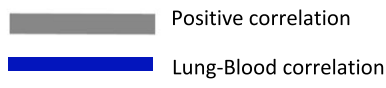

$|r|=0.3 \quad|r|=0.8$

Fig. 3 Multilevel (lung and blood) Spearman correlation network $(|r|>0.3, p<0.05)$ for all participants ( $n=65)$ of lung (green), peripheral blood (red) immune cell populations, lung function variables (blue) and general systemic inflamatory biomarkers (yellow). Positive correlations are represented with a continuous edge while the negatives are with a discontinuous edge. Edge witdth is proportional to the strength of the correlation. Node size is proportional to the mean percentatge of CD45\% cells of the population. Blue links are used to highlight correlations between lung and blood markers. For further explanations, see text

Table 3 Top Genes differentially expressed in Controls vs. COPD in the LTRC consortium dataset

\begin{tabular}{|c|c|c|c|c|c|c|c|c|c|}
\hline & Module & symbol & adj.P.Val & $\log F C$ & & Module & symbol & adj.P.Val & $\log F C$ \\
\hline 1 & Yellow & FGG & 5.54E-06 & -1.92 & 1 & Yellow & KRT4 & $2.10 \mathrm{E}-06$ & 0.93 \\
\hline 2 & Greenyellow & PLA2G2A & 2.21E-03 & -1.03 & 2 & Yellow & SLITRK6 & $1.76 \mathrm{E}-04$ & 0.76 \\
\hline 3 & Blue & BNC1 & 9.91E-04 & -0.99 & 3 & Yellow & CDHR3 & $2.57 \mathrm{E}-02$ & 0.70 \\
\hline 4 & Greenyellow & POU2AF1 & $6.61 \mathrm{E}-05$ & -0.93 & 4 & Yellow & CFAP74 & $3.68 \mathrm{E}-02$ & 0.60 \\
\hline 5 & Greenyellow & MZB1 & 1.96E-04 & -0.84 & 5 & Yellow & TNNI3 & $1.86 \mathrm{E}-03$ & 0.56 \\
\hline 6 & Greenyellow & TNFRSF17 & 7.95E-04 & -0.76 & 6 & Yellow & SEC14L4 & 7.42E-05 & 0.55 \\
\hline 7 & Greenyellow & IGDCC4 & 4.07E-05 & -0.68 & 7 & Blue & PRPH & $9.61 \mathrm{E}-06$ & 0.54 \\
\hline 8 & Greenyellow & CPXM1 & $3.28 \mathrm{E}-03$ & -0.68 & 8 & Yellow & SEC14L3 & 4.30E-02 & 0.53 \\
\hline 9 & Greenyellow & COL14A1 & 5.88E-05 & -0.64 & 9 & Yellow & PRMT8 & 1.07E-02 & 0.51 \\
\hline 10 & Greenyellow & CTHRC1 & 1.50E-03 & -0.61 & 10 & Yellow & WWA3A & 3.99E-02 & 0.46 \\
\hline
\end{tabular}


tissue including genes that have been previously associated with the pathobiology of COPD; and, finally (3) the immune cell multi-level correlation network shows some weak relations between lung and blood cells, the strongest one between the absolute number of blood leukocytes and the proportion of lung macrophages and $\mathrm{T}$ cells.

Many previous studies have investigated the pulmonary and systemic inflammatory response in COPD [6-8]. It is generally accepted that the absolute number of T-cells, both CD8+ cytotoxic T lymphocytes [24] and CD4+ T lymphocytes (polarized towards a TH1 response) [25], increase in patients with severe-very severe COPD. Our results in lung tissue show a reduction in the proportion of infiltrating $\mathrm{T}$ cells which was mostly related to smoking and only marginally to the presence of COPD. Apparently, therefore, our results do not agree with previous reports. However, to interpret them appropriately, it is important to consider that: (1) because our methodology does not allow the quantification of the absolute number of infiltrating cells, our results refer to their relative proportion (not to their absolute numbers); (2) we studied patients with mild-moderate, not severe-very severe, COPD. In fact, a recent study in bronchoalveolar lavage fluid (BALF) obtained from patients with mild-moderate COPD (GOLD grades 1-2) also reported a decrease in the proportion of T CD4+ cells and a clear effect of active smoking on cell population distribution [26]. This is indeed in line with our results and highlighting that GOLD grade and current smoking have both to be carefully considered when investigating the inflammatory response of COPD. On the other hand, it is well established that $M \phi$ are increased in BALF and lung tissue of COPD patients [27]. Our results are in keeping with these previous observations and extend them by showing that this increase is related independently both to active smoking and, to a lesser extent, to the presence of the disease.

Several previous studies have investigated lung transcriptomics in COPD [28, 29], but to our knowledge none has previously related the transcriptomic status with the proportion of infiltrating macrophages. Using WGCNA we identified four transcriptomic co-expression modules that were associated with the proportion of lung $M \phi$ independently of the level of airflow limitation and smoking status. Interestingly one module (GreenYellow) was associated with the percentage of CD80 + CD163+ macrophages and enriched in ontologies related to extracellular matrix organization and collagen metabolism. Interestingly this module presented a negative correlation with the levels of DLCO, in agreement with the findings of the multi-level correlation network. This module included genes differentially expressed in other lung tissue cohorts as: COL14A1, SFRP2 and CCDC80. Several reports have identified a differential expression of collagen genes in COPD [10], while SFRP2 has been related to a down-regulation of the WNT pathway and CCDC80 is expressed by alveolar macrophages [30]. Although this is a starting point for future research aimed at understanding mechanistically the pathogenic relevance of these associations, is in line with our previous reports of an abnormal catabasis in lung tissue macrophages of patients with COPD [31].

Finally, previous studies reported alterations in specific subsets of circulating blood cells, specifically an increase in total leukocytes and neutrophils in relation to current smoking has been described $[5,32]$. But none used network analysis to relate lung and blood immune cells with clinical characteristics. Our results showed that circulating white cells (both total leukocyte counts) were negatively correlated with the percentage of lung T-cells and positively correlated with the percentage of lung $\mathrm{M} \phi$. Yet, the overall relation between the two compartments (lung and blood) is weak, so the blood immune cell composition cannot be used to predict the inflammatory status of the lung tissue.

The strengths of the study are that, for the first time it profiles a wide variety of immune cells, both in lung tissue and circulating blood, of a relatively large population of patients with mild moderated COPD and controls and uses multi-level network analysis to relate the immune response of the pulmonary and systemic compartments. Likewise, it is the first to investigate the lung transcriptome with the immune cell infiltrate. On the other hand, the limitations of the study are that all participants had surgically resectable lung cancer and that, although analysed lung samples were tumor-free, this can be a potentially confounding factor in our analysis. However, if this was the case, it might have affected similarly all samples analysed. Finally, it would have been interesting to assess how the immune infiltrate changes according to both current smoking and inhaled corticosteroid treatment (ICS) treatment, yet our cohort is underpowered to do these analysis as only COPD 8 patients were under ICS treatment.

\section{Conclusions}

This study, by integrating high throughput analytical techniques in a unique, multi-level data set, provides novel information on the relation of the pulmonary and systemic inflammatory response that characterizes COPD. Our main findings highlight the role of lung macrophages and the active smoking status in the pathobiology of COPD. All in all, these observations contribute to a better understanding of COPD pathobiology.

\section{Additional files}

Additional file 1: Online Supplement. (DOCX $576 \mathrm{~kb}$ )

Additional file 2: Supplementary Figures. (PDF 1969 kb) 


\section{Abbreviations}

BMl: Body mass index; COPD: Chronic obstructive pulmonary disease; DC: Dendritic cells; $M \varphi$ : Macrophages; NKT: Natural killer T cells; WGCNA: Weighted Gene Co-expression Network Analysis

\section{Acknowledgements}

Authors thank all patients in the study for their willingness to contribute to medical research and Ms. Gemma Sunyer for her excellent technical support during the study. We also want to thank to technicians (Ms. Mireia Anton and Noemí de Moner) of Flow-cytometry unit in immunology service, for their help and assistance in cytometry. This work was developed at the Centre de Recerca Biomèdica Cellex, Barcelona, Spain.

\section{Declarations}

The Ethic Committee of Hospital Clinic de Barcelona approved the study (HCB-2012/7731), and all participants signed their informed consent.

\section{Authors' contributions}

Study conception and design: (RF, GN), data acquisition: (AL-G, TC, LM, SC-R, TG, MJ, MAF), data analysis: (TC, AL-G, RF, GN, MAF, MJ), manuscript preparation: (RF, TC, AA), manuscript revision: All. All authors read and approved the final manuscript.

\section{Funding}

This work was supported by unrestricted grants from Menarini, Instituto de Salud Carlos III (PI17/000369, PI18/0103), Fondos Feder una nueva manera de hacer Europa. Rosa Faner is recipient of a Miguel Servet Research Program Contract (FEDER, CP16/00039).

\section{Availability of data and materials}

Data is available from GEO\#(GSE103174) and from authors on a reasonable request.

\section{Competing interests}

The authors declare that they have no competing interests.

\section{Publisher's Note}

Springer Nature remains neutral with regard to jurisdictional claims in published maps and institutional affiliations.

\section{Author details}

${ }^{1}$ CIBER Enfermedades Respiratorias, Barcelona, Spain. ${ }^{2}$ Institut de Recerca Biomedica August Pi i Sunyer (IDIBAPS), Barcelona, Spain. ${ }^{3}$ Respiratory Institute, Hospital Clinic, University of Barcelona, Barcelona, Spain. ${ }^{4}$ Immunology Service, Centre Diagnostic Biomèdic, Hospital Clinic, University of Barcelona, Barcelona, Spain. ${ }^{5}$ Flow Cytometry Facility, Institut de Recerca Germans Trias I Pujol, Barcelona, Spain. ${ }^{6}$ CIBERES, IDIBAPS-CELLEX. Facultat de Medicina P2A, c/Casanova 143, 08036 Barcelona, Spain.

Received: 22 March 2019 Accepted: 19 June 2019

\section{Published online: 12 July 2019}

\section{References}

1. Faner $\mathrm{R}$, Cruz $\mathrm{T}$, Agusti $\mathrm{A}$. Immune response in chronic obstructive pulmonary disease. Expert Rev Clin Immunol. 2013;9:821-33.

2. Vogelmeier CF, Criner GJ, Martinez FJ, Anzueto A, Barnes PJ, Bourbeau J, Celli BR, Chen R, Decramer M, Fabbri LM, et al. Global strategy for the diagnosis, management, and prevention of chronic obstructive lung disease 2017 report. GOLD executive summary. Am J Respir Crit Care Med. 2017;195:557-82

3. Hodge G, Mukaro V, Reynolds PN, Hodge S. Role of increased CD8/ CD28(null) T cells and alternative co-stimulatory molecules in chronic obstructive pulmonary disease. Clin Exp Immunol. 2011;166:94-102.

4. Faner R, Gonzalez N, Cruz T, Kalko SG, Agusti A. Systemic inflammatory response to smoking in chronic obstructive pulmonary disease: evidence of a gender effect. PLoS One. 2014;9:e97491.

5. Agusti A, Edwards LD, Rennard SI, MacNee W, Tal-Singer R, Miller BE, Vestbo J, Lomas DA, Calverley PM, Wouters E, et al. Persistent systemic inflammation is associated with poor clinical outcomes in COPD: a nove phenotype. PLoS One. 2012;7:e37483.
6. Hogg JC, Chu F, Utokaparch S, Woods R, Elliott WM, Buzatu L, Cherniack RM, Rogers RM, Sciurba FC, Coxson HO, Pare PD. The nature of small-airway obstruction in chronic obstructive pulmonary disease. NEnglJMed. 2004;350:2645-53.

7. Cosio MG, Saetta M, Agusti A. Immunologic aspects of chronic obstructive pulmonary disease. NEnglJMed. 2009;360:2445-54.

8. Brusselle GG, Joos GF, Bracke KR. New insights into the immunology of chronic obstructive pulmonary disease. Lancet. 2011;378:1015-26.

9. Van Pottelberge GR, Bracke KR, Van den Broeck S, Reinartz SM, van Drunen CM, Wouters EF, Verleden GM, Vermassen FE, Joos GF, Brusselle GG. Plasmacytoid dendritic cells in pulmonary lymphoid follicles of patients with COPD. Eur Respir J. 2010;36:781-91.

10. Faner R, Cruz T, Casserras T, Lopez-Giraldo A, Noell G, Coca I, Tal-Singer R, Miller B, Rodriguez-Roisin R, Spira A, et al. Network analysis of lung transcriptomics reveals a distinct B cell signature in emphysema. Am J Respir Crit Care Med. 2016;193(11):1242-53.

11. Morrow JD, Zhou X, Lao T, Jiang Z, DeMeo DL, Cho MH, Qiu W, Cloonan S, Pinto-Plata V, Celli B, et al. Functional interactors of three genome-wide association study genes are differentially expressed in severe chronic obstructive pulmonary disease lung tissue. Sci Rep. 2017;7:44232.

12. Obeidat M, Nie Y, Fishbane N, Li X, Bosse Y, Joubert P, Nickle DC, Hao K, Postma DS, Timens W, et al. Integrative genomics of emphysema associated genes reveals potential disease biomarkers. Am J Respir Cell Mol Biol. 2017; 57(4):411-8

13. de Vries M, Faiz A, Woldhuis RR, Postma DS, de Jong TV, Sin DD, Bosse $Y$, Nickle DC, Guryev V, Timens W, et al. Lung tissue gene-expression signature for the ageing lung in COPD. Thorax. 2017;73(7). https://doi.org/10.1136/ thoraxjinl-2017-210074

14. Stampfli MR, Anderson GP. How cigarette smoke skews immune responses to promote infection, lung disease and cancer. Nat Rev Immunol. 2009;9:377-84.

15. Barnes PJ, Celli BR. Systemic manifestations and comorbidities of COPD. Eur Respir J. 2009;33:1165-85.

16. Agusti A, Gea J, Faner R. Biomarkers, the control panel and personalized COPD medicine. Respirology. 2016;21:24-33.

17. Roca J, Sanchis J, Agusti-Vidal A, Segarra F, Navajas D, Rodriguez-Roisin R, Casan P, Sans S. Spirometric reference values from a Mediterranean population. Bull Eur Physiopathol Respir. 1986:22:217-24.

18. Computing. RCTRFfS: R: A language and environment for statistical computing. 2016.

19. Shannon P, Markiel A, Ozier O, Baliga NS, Wang JT, Ramage D, Amin N, Schwikowski B, Ideker T. Cytoscape: a software environment for integrated models of biomolecular interaction networks. Genome Res. 2003;13:2498-504.

20. Yu YR, O'Koren EG, Hotten DF, Kan MJ, Kopin D, Nelson ER, Que L, Gunn $\mathrm{MD}$. A protocol for the comprehensive flow cytometric analysis of immune cells in Normal and inflamed murine non-lymphoid tissues. PLoS One. 2016; 11:e0150606.

21. Langfelder P, Horvath S. WGCNA: an R package for weighted correlation network analysis. BMC Bioinformatics. 2008;9:559.

22. Noell G, Cosio BG, Faner R, Monso E, Peces-Barba G, de Diego A, Esteban C, Gea J, Rodriguez-Roisin R, Garcia-Nunez M, et al. Multi-level differential network analysis of COPD exacerbations. Eur Respir J. 2017:50(3). https://doi. org/10.1183/13993003.00075-2017.

23. Barjaktarevic I, Springmeyer S, Gonzalez X, Sirokman W, Coxson HO, Cooper CB. Diffusing capacity for carbon monoxide correlates best with tissue volume from quantitative CT scanning analysis. Chest. 2015;147:1485-93.

24. Saetta M, Di Stefano A, Turato G, Facchini FM, Corbino L, Mapp CE, Maestrelli P, Ciaccia A, Fabbri LM. CD8+ T-lymphocytes in peripheral airways of smokers with chronic obstructive pulmonary disease. Am J Respir Crit Care Med. 1998;157:822-6.

25. Turato $G$, Zuin R, Miniati M, Baraldo S, Rea F, Beghé B, Monti S, Formichi B, Boschetto $P$, Harari $S$, et al. Airway inflammation in severe chronic obstructive pulmonary disease: relationship with lung function and radiologic emphysema. Am J Respir Crit Care Med. 2002;166:105-10.

26. Forsslund H, Mikko M, Karimi $R$, Grunewald J, Wheelock $\AA$, Wahlström J, Sköld CM. Distribution of T-cell subsets in BAL fluid of patients with mild to moderate COPD depends on current smoking status and not airway obstruction. Chest. 2014;145:711-22.

27. Molet $\mathrm{S}$, Belleguic $\mathrm{C}$, Lena $\mathrm{H}$, Germain N, Bertrand CP, Shapiro SD, Planquois JM, Delaval P, Lagente V. Increase in macrophage elastase (MMP-12) in 
lungs from patients with chronic obstructive pulmonary disease. Inflamm Res. 2005;54:31-6.

28. Gower AC, Steiling K, Brothers JF, Lenburg ME, Spira A. Transcriptomic studies of the airway field of injury associated with smoking-related lung disease. Proc Am Thorac Soc. 2011;8:173-9.

29. Zeskind JE, Lenburg ME, Spira A. Translating the COPD transcriptome: insights into pathogenesis and tools for clinical management. Proc Am Thorac Soc. 2008:5:834-41.

30. Poczobutt JM, De S, Yadav VK, Nguyen TT, Li H, Sippel TR, Weiser-Evans MC, Nemenoff RA. Expression profiling of macrophages reveals multiple populations with distinct biological roles in an immunocompetent Orthotopic model of lung Cancer. J Immunol. 2016;196:2847-59.

31. Noguera A, Gomez C, Faner R, Cosio B, Gonzalez-Periz A, Claria J, Carvajal A, Agusti A. An investigation of the resolution of inflammation (catabasis) in COPD. Respir Res. 2012;13:101.

32. Halper-Stromberg E, Yun JH, Parker MM, Tal Singer R, Gaggar A, Silverman EK, Leach S, Bowler RP, Castaldi PJ. Systemic markers of adaptive and innate immunity are associated with COPD severity and Spirometric disease progression. Am J Respir Cell Mol Biol. 2018;58(4):500-9. https://doi.org/10. 1165/rcmb.2017-03730C

Ready to submit your research? Choose BMC and benefit from:

- fast, convenient online submission

- thorough peer review by experienced researchers in your field

- rapid publication on acceptance

- support for research data, including large and complex data types

- gold Open Access which fosters wider collaboration and increased citations

- maximum visibility for your research: over $100 \mathrm{M}$ website views per year

At $\mathrm{BMC}$, research is always in progress.

Learn more biomedcentral.com/submissions 